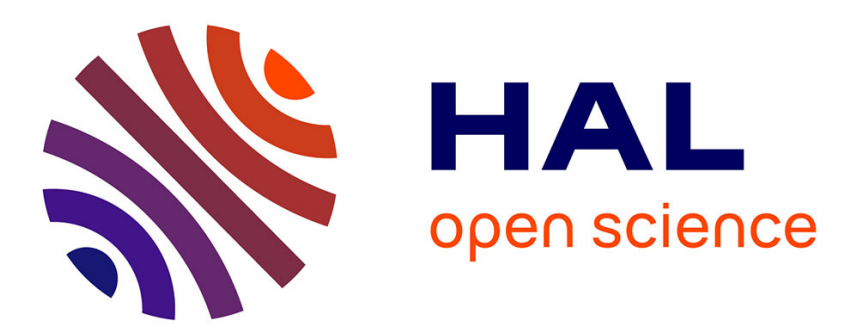

\title{
Expansion of the $\mathbf{H}+2$ ground state energy in inverse powers of the distance between the two protons
}

E. Brezin, J. Zinn-Justin

\section{To cite this version:}

E. Brezin, J. Zinn-Justin. Expansion of the $\mathrm{H}+2$ ground state energy in inverse powers of the distance between the two protons. Journal de Physique Lettres, 1979, 40 (19), pp.511-512. 10.1051/jphyslet:019790040019051100 . jpa-00231676

\section{HAL Id: jpa-00231676 https://hal.science/jpa-00231676}

Submitted on 1 Jan 1979

HAL is a multi-disciplinary open access archive for the deposit and dissemination of scientific research documents, whether they are published or not. The documents may come from teaching and research institutions in France or abroad, or from public or private research centers.
L'archive ouverte pluridisciplinaire HAL, est destinée au dépôt et à la diffusion de documents scientifiques de niveau recherche, publiés ou non, émanant des établissements d'enseignement et de recherche français ou étrangers, des laboratoires publics ou privés. 


\title{
Expansion of the $\mathrm{H}_{2}^{+}$-ground state energy in inverse powers of the distance between the two protons
}

\author{
E. Brezin and J. Zinn-Justin \\ Division de la Physique, Service de Physique théorique, CEN, Saclay, B.P. no 2, 91190 Gif-sur-Yvette, France
}

(Reçu le 9 juillet 1979, accepté le 20 août 1979)

Résumé. - L'énergie du fondamental de l'ion moléculaire $\mathrm{H}_{2}^{+}$a été développée en puissances de l'inverse de la distance entre les deux protons

$$
E=\sum \frac{a_{n}}{R^{n}}
$$

Il est expliqué ici que les coefficients $a_{n}$ se comportent pour $n$ très grand selon la loi

$$
a_{n} \simeq-\frac{2}{e^{2}} \frac{(n+1) !}{2^{n+1}}
$$

Abstract. - The ground state energy of the ionized hydrogen molecule $\mathrm{H}_{2}^{+}$has been expanded in inverse powers of the distance between the two protons

$$
E=\sum \frac{a_{n}}{R^{n}}
$$

It is explained here that for $n$ very large the coefficients $a_{n}$ behave as

$$
a_{n} \simeq-\frac{2}{e^{2}} \frac{(n+1) !}{2^{n+1}} .
$$

In a recent article $\mathbf{J}$. Morgan and $\mathbf{B}$. Simon [1] have studied the expansion of the ground state energy of the ion $\mathrm{H}_{2}^{+}$in inverse powers of the distance between the two protons :

$$
\begin{gathered}
H=-\frac{1}{2} \Delta-\left(\frac{1}{r}+\frac{1}{|\mathbf{R}-\mathbf{r}|}\right) \\
E=\sum_{n=0}^{\infty} \frac{a_{n}}{R^{n}} .
\end{gathered}
$$

It is shown in their study that the series (2) is asymptotic and presumably divergent and not Borel summable. This is conjectured on the basis of a numerical study by the same authors which indicates that the following asymptotic law for the coefficients $a_{n}$ seems to hold :

$$
a_{n} \underset{n \rightarrow \infty}{\sim}-C_{0} \frac{(n+1) !}{2^{n+1}}
$$

with $C_{0}$ a negative constant estimated to lie in the range $(0.27-0.30)$.

As pointed out by these authors, it is not surprising that the series diverges in this way, since the expansion in powers of $1 / R$ begins with a state localized around the origin. The expansion around this state is never able to reproduce the true wave function which is symmetric under the exchange $\mathbf{r} \leftrightarrow(\mathbf{R}-\mathbf{r})$ and thus peaked around the two centres. The situation is analogous to that of the simpler one-dimensional double well problem [2].

It is known [3] that one can relate the large order behaviour of this expansion to the splitting in energy of the two lowest lying states, symmetric and antisymmetric under the exchange $\mathbf{r} \leftrightarrow(\mathbf{R}-\mathbf{r})$. The derivation relies on the fact that the large order estimates are related to well separated instantonantiinstanton paths for which the action is twice the instanton action, and that the quantum fluctuations are the square of those around the single instanton 
Table I.

$$
\begin{aligned}
\bar{a}_{n} & =-a_{n} \frac{2^{n+1}}{(n+1) !} \text { is taken from Ref. [1] } \\
b_{n} & =n \bar{a}_{n}-(n-1) \bar{a}_{n-1} \\
c_{n} & =\frac{1}{2}\left(b_{n}-(n-2) b_{n-1}\right) .
\end{aligned}
$$

$\bar{a}_{n}, b_{n}, c_{n}$ should approach the same limit with deviations of order $1 / n, 1 / n^{2}$ and $1 / n^{3}$ respectively.

$\begin{array}{cccc}n & \bar{a}_{n} & b_{n} & c_{n} \\ -20 & 0.28198843 & 0.2917235 & 0.2707493 \\ 21 & 0.28231898 & 0.2889300 & 0.2623919 \\ 22 & 0.28252996 & 0.2869605 & 0.2672661 \\ 23 & 0.28264016 & 0.2850646 & 0.2651568 \\ 24 & 0.28268316 & 0.2836722 & 0.2683558 \\ 25 & 0.28266847 & 0.2823159 & 0.2667190 \\ 26 & 0.28261603 & 0.2813050 & 0.2691745 \\ 27 & 0.28253070 & 0.2803121 & 0.2679007 \\ 28 & 0.28242440 & 0.2795543 & 0.2697026 \\ 29 & 0.28229960 & 0.2788052 & 0.2686924 \\ 30 & 0.28216359 & 0.2782193 & 0.2700167 \\ 31 & 0.28201764 & 0.2776391 & 0.2692268 \\ 32 & 0.28186632 & 0.2771754 & 0.2702193 \\ 33 & 0.28171021 & 0.2767147 & 0.2695737 \\ 34 & 0.28155226 & 0.2763399 & 0.2703434 \\ 35 & 0.28139270 & 0.2759677 & 0.2698255 \\ 36 & 0.28123342 & 0.2756586 & 0.2704049 \\ 37 & 0.281107443 & 0.2753508 & 0.2699638\end{array}$

path. We make the assumption that the same features hold for the more singular Coulomb problem.
This splitting has been calculated by Landau-Lifshitz [4] for large $R$ :

$$
\frac{1}{2} \Delta E \underset{R \operatorname{large}}{\simeq} \frac{2}{e} R e^{-R}
$$

The formula relating the asymptotic behaviour of the coefficients of the $1 / R$ expansion to $\Delta E(R)$ is

$$
a_{n} \underset{n \text { large }}{\simeq} \int_{0}^{\infty} \mathrm{d} R R^{n-1}\left(\frac{1}{2} \Delta E(R)\right)^{2}
$$

and thus for $n$ large it requires an estimate of the large $R$ behaviour of $\Delta E(R)$. Using the result (4) this leads to

$$
a_{n} \simeq-C_{0} \frac{(n+1) !}{2^{n+1}}
$$

with

$$
C_{0}=\frac{2}{e^{2}}=0.27067057 \text {. }
$$

It is interesting to compare this result to the numbers given by Morgan and Simon [1]. The convergence of the sequence $\bar{a}_{n}=-\frac{2^{n+1} a_{n}}{(n+1) !}$ is not very rapid and we have used a Neville table [5]. A further numerical analysis suggests that

$$
\bar{a}_{n}=\frac{2}{e^{2}}\left(1+\frac{2}{n}+0\left(\frac{1}{n^{2}}\right)\right) .
$$

We wish to thank Hector de Vega for helpful discussions.

\section{References}

[1] Morgan, J. and Simon, B., Princeton Univ. preprint.

[2] Brezin, E., Parisi, G. and Zinn-Justin, J., Phys. Rev. D 16 (1977) 408.

[3] Bogomolny, E. B. and Fateyev, V. A., Phys. Lett. 71B(1977) 93. ZinN-Justin, J. (Princeton Univ. Lectures, unpublished).
[4] LANDAU, L. D. and LIFShITZ, E. M., Quantum mechanics (Pergamon press Oxford) 1965, Second Edition p. 292.

[5] It seems that for $n$ larger than 38 the numbers of ref. [1] are affected by increasing numerical errors and they have not been included in our analysis. 